\title{
Screening for delirium within intensive care units in scotland: a national survey
}

\author{
AW McGuire*, LG Young, JAG Davidson \\ From ESICM LIVES 2015 \\ Berlin, Germany. 3-7 October 2015
}

\section{Introduction}

Delirium is defined by the Diagnostic and Statistical Manual of Mental Disorders (DSM-IV) as a disturbance in consciousness and alteration in cognition over a short time period. It tends to fluctuate throughout the day and is evident from the clinical history, examination or investigations that delirium is as a result of a medical condition, drug withdrawal or intoxication. All of the above factors need to be present for a diagnosis of delirium to be made. ${ }^{1}$

In the UK around $65 \%$ of unwell ventilated patients in intensive care experience delirium. ${ }^{2}$ This can be challenging to diagnose in the severely unwell patient. Delirium is associated with increased morbidity and mortality, increased length of hospital stay and long term disability and dementia. ${ }^{2}$ The American College of Critical Care Medicine and Intensive Care society recommend daily screening for delirium to allow timely identification and appropriate treatment. Two recommended scoring systems for identification of delirium are the Intensive Care Delirium Scoring Checklist (ICDSC) and the Confusion Assessment Method for Intensive Care (CAM-ICU). ${ }^{2}$

\section{Objectives}

To assess whether intensive care units within Scotland are screening for delirium on a daily basis and to test awareness of the current methods used for screening.

\section{Methods}

This was a national survey of all 23 adult intensive care units in Scotland, via telephone over the course of one day. Nursing or medical staff in each unit, familiar with local policy were questioned to ensure validity of survey responses. Each unit was asked whether they screen for delirium on a daily basis and if they were aware of any

Victoria Infirmary/ NHS Greater Glasgow \& Clyde, Intensive Care, Glasgow, United Kingdom

(c) 2015 McGuire et al.; This is an Open Access article distributed under the terms of the Creative Commons Attribution License (http:// creativecommons.org/licenses/by/4.0), which permits unrestricted use, distribution, and reproduction in any medium, provided the original work is properly cited. screening tools used for delirium. Those units who screened for delirium daily were asked which screening methods they used (CAM-ICU or ICDSC) and whether nursing/medical staff or a combination carried this out primarily.

\section{Results}

When asked 16 out of the 23 (69.57\%) units in Scotland stated they screened for delirium on a daily basis.

Screening was done primarily by the nursing staff in $50 \%$ (8) of these units, with the other $25 \%$ by doctors and $25 \%$ both medical and nursing staff.

Of the $91.3 \%$ of units aware of recommended screening tools for delirium, all stated that they used the CAM-ICU screen.

\section{Conclusion}

Daily screening for delirium using either CAM-ICU or ICDSC is the gold standard for early identification of a

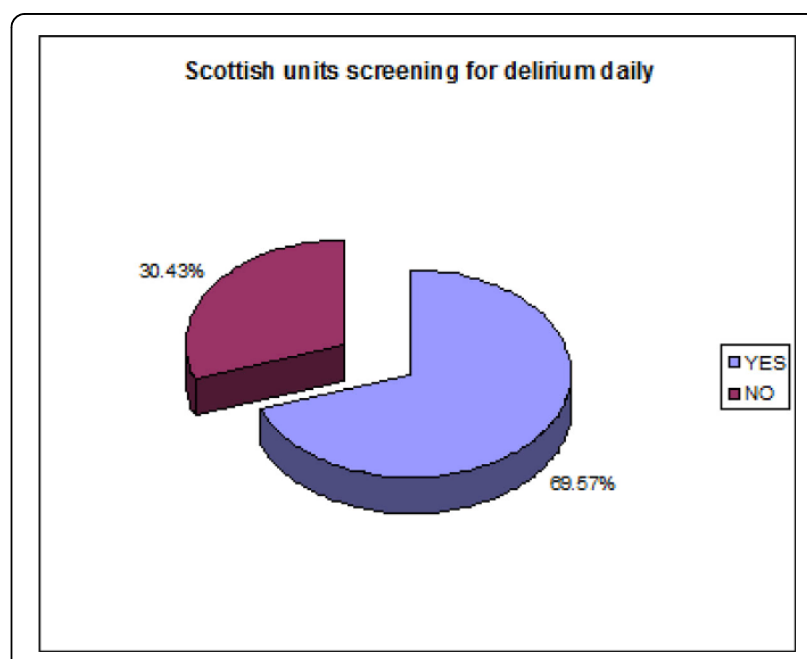

Figure 1 Scottish units screening for delirium. 
Table 1 Who screens for delirium?

\begin{tabular}{cccc}
\hline & Medical staff & Nursing Staff & Both \\
\hline Number & 4 & 8 & 4 \\
\hline Percentage & $25 \%$ & $50 \%$ & $25 \%$ \\
\hline
\end{tabular}

patient with delirium. Increased awareness of delirium through screening allows a prompt assessment of causes and a more sensitive holistic and pharmacological patient management plan to limit morbidity and mortality. In general, intensive care units in Scotland are screening for delirium daily and have a good awareness of the methods used to screen for delirium.

Published: 1 October 2015

\section{References}

1. King J, Gratirix A: Delirium in intensive care Contin Educ Anaesth Crit Care Pain. 2009, 9(5):144-147.

2. Page Valerie: Delirium in intensive care patients. BMJ 2012, 344:e346.

doi:10.1186/2197-425X-3-S1-A727

Cite this article as: McGuire et al:: Screening for delirium within

intensive care units in scotland: a national survey. Intensive Care Medicine Experimental 2015 3(Suppl 1):A727.

\section{Submit your manuscript to a SpringerOpen ${ }^{\mathcal{O}}$ journal and benefit from:}

- Convenient online submission

- Rigorous peer review

- Immediate publication on acceptance

- Open access: articles freely available online

- High visibility within the field

- Retaining the copyright to your article 